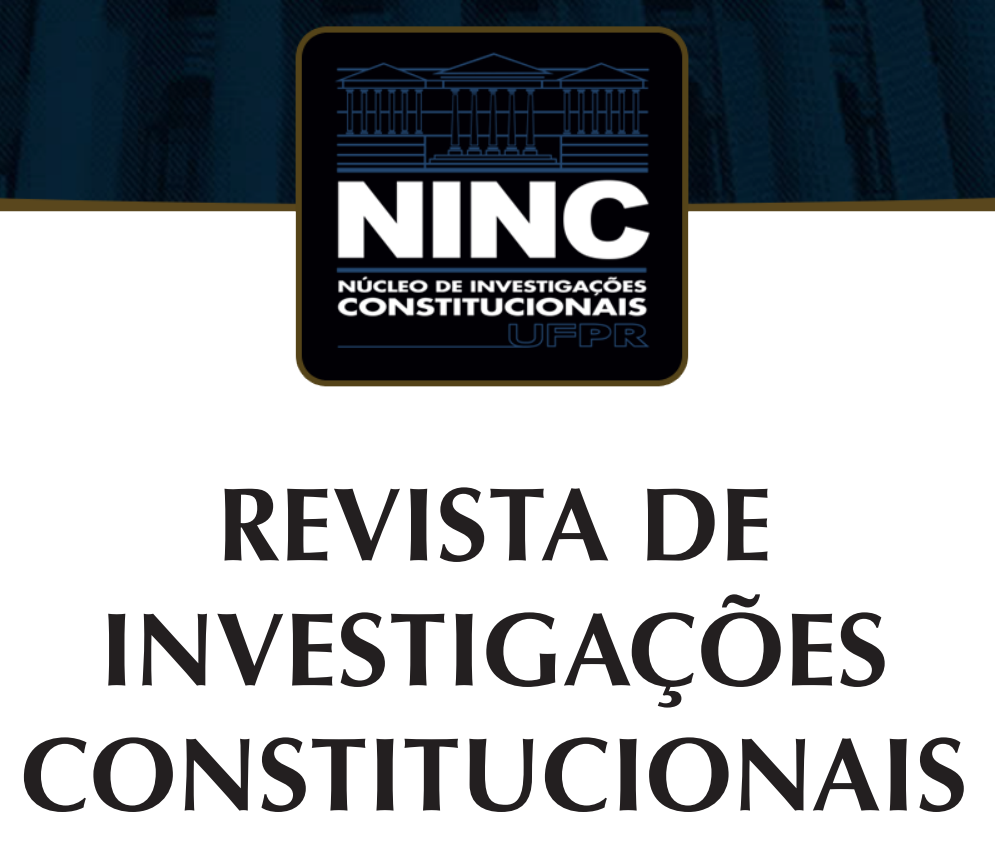

JOURNAL OF CONSTITUTIONAL RESEARCH

vol. 7 | n. 2 | maio/agosto 2020 | ISSN 2359-5639 | Periodicidade quadrimestral Curitiba | Núcleo de Investigações Constitucionais da UFPR | www.ninc.com.br 


\title{
Revocatoria popular y revocatoria partidaria en Panamá: diseño institucional y casos de aplicación
}

\section{Popular recall and party recall in Panama: institutional design and cases}

\author{
MARÍA LAURA EBERHARDT ${ }^{\mathrm{l}, *}$ \\ 'Universidad de Buenos Aires (Buenos Aires, Argentina) \\ laura_rafaela@yahoo.com.ar \\ https://orcid.org/0000-0003-4447-5641 \\ Recebido/Received: 16.01.2019 / January $16^{\text {th }}, 2019$ \\ Aprovado/Approved: 30.10 .2020 / October 30 ${ }^{\text {th }}, 2020$
}

\section{Resumen}

El presente artículo constituye uno de los resultados de un proyecto de investigación enfocado en analizar la revocatoria de mandato como un mecanismo de participación y control ciudadano, adoptado en mayor medida desde fines de los años 80 por varios países de América Latina en un clima de crisis de la representación política. El caso Panamá es doblemente interesante para su estudio, debido a que, además de la revocatoria popular, incluye una modalidad especial de recall: la revocatoria partidaria o "antitránsfuga". Para su abordaje, se realiza un análisis en profundidad y comparado de la legislación nacional que crea y reglamenta estos dos institutos, as

\section{Abstract}

This article is one of the results of a research process focused on analyzing the recall as a mechanism for citizen participation and control, that was adopted to a greater extent since the late 1880 by several Latin American countries in a climate of crisis of political representation. The case of $\mathrm{Pa}$ nama is doubly interesting for its study, due to the fact that, in addition to the popular recall, it includes a special modality of recall: the party recall or "anti-transgression" one. For its approach, an in-depth and comparative analysis is made of the national legislation that creates and regulates these institutes, as well as an empirical study of the only two cases of party recall application registered so far. The conclusions

Como citar esse artigo/How to cite this article: EBERHARDT, María Laura. Revocatoria popular y revocatoria partidaria en Panamá: diseño institucional y casos de aplicación. Revista de Investigações Constitucionais, Curitiba, vol. 7, n. 2, p. 401-427, maio/ago. 2020. DOI: 10.5380/rinc.v7i2.64349.

"Profesora de la Universidad de Buenos Aires (Buenos Aires, Argentina) y Universidad Nacional Arturo Jauretche. Posdoctorado de la Facultad de Derecho (UBA). Doctora en Ciencia Política (UNSAM). Magíster en Ciencia Política y Sociología (FLACSO). Licenciada en Ciencia Política (UBA). Investigadora del Consejo Nacional de Investigaciones Científicas y Técnicas. Directora de proyecto de Investigación UBACyT. E-mail: laura_rafaela@yahoo.com.ar. 
como un estudio empírico de los dos únicos casos de aplicación de revocatoria partidaria registrados hasta el momento. En las conclusiones se sintetizan los alcances y limitaciones de la existencia y uso de la revocatoria como un instrumento de profundización democrática.

Palabras clave: revocatoria popular; revocatoria partidaria; participación y control ciudadano; democracia directa; Panamá. summarize the scope and limitations of the existence and use of the recall as an instrument of democratic deepening.

Keywords: Popular recall; party recall; citizen participation and control, direct democracy, Panamá.

\section{SUMARIO}

1. Introducción y marco teórico; 2. Revocatoria popular y revocatoria partidaria en Panamá: la normativa; 2.1. La Constitución Política de la República de Panamá, 11 de octubre de 1972; 2.2. La Ley № 19, 9 de julio de 1980; 2.3. Constitución Política de la República de Panamá de 1972 con reformas de 1978 y 1983, 4 de mayo de 1983; 2.4. Constitución Política de la República de Panamá, Acto Legislativo № 1, 27 de abril de 2004; 2.5. La Ley N 60 Que reforma el Código Electoral, 29 de diciembre de 2006; 2.6. La Ley $\mathrm{N}^{\circ} 14$ del 13 de abril de 2010; 2.7 . La Ley $\mathrm{N}^{\circ} 4,7$ de febrero de 2013; 3. La revocatoria de mandato en los hechos; 4 . Conclusiones; $\mathbf{5}$. Referencias.

\section{INTRODUCCIÓN Y MARCO TEÓRICO}

La revocatoria de mandato popular o clásica es un mecanismo de participación y control ciudadano cuya incorporación en América Latina se enmarca en mayor medida en la tercera ola de la democratización ${ }^{12}$ y las reformas políticas y constitucionales de los años '90. Forma parte del conjunto de innovaciones adoptadas principalmente por iniciativa de los gobernantes como respuesta a un clima de descontento y apatía ciudadana respecto de la política y de sus representantes, más conocido como crisis de la representación.

Es considerada un instrumento de "democracia directa", la que abarca un grupo de mecanismos que permite a los ciudadanos decidir sobre materias específicas directamente en las urnas. Esos mecanismos son instrumentos de decisión política ejercidos a través del sufragio directo y universal ${ }^{3}$. Su finalidad es hacer que los ciudadanos participen colectiva y directamente en el procedimiento de toma de decisión, más que para elegir a sus representantes, para tomar sus propias decisiones ${ }^{4}$. Además

\footnotetext{
HUNTINGTON, Samuel. La Tercera ola. La democratización a finales de Siglo XX. Barcelona: Paidós Ibérica, 1994.

2 Este autor ubica la tercera ola de la democratización desde 1974, durante los 15 años siguientes al final de la dictadura portuguesa, ocurrida en aproximadamente treinta países de Europa, Asia y América Latina, cuando los regímenes autoritarios fueron emplazados por otros democráticos

3 ALTMAN, David. Democracia Directa en el continente americano: ¿autolegitimación gubernamental o censura ciudadana? Política y Gobierno, México D. F., vol. 12, n. 2, p. 203-232, 2005. p. 204.

4 PAYNE J., Mark; Zovatto G., Daniel; CARRILLO-FLÓREZ, Fernando; Allamand Z., Andrés. Democracies in Development: Politics and Reform in Latin America. Washington D.C: Inter-American Development Bank - International Institute for Democracy and Electoral Assistance, 2002.
} 
de la revocatoria, se incluye en esta categoría de democracia directa al plebiscito y al referéndum, cuyas opciones abiertas a la población también se dirimen en el si o el no a una pregunta concreta.

El también llamado recall constituye una herramienta novedosa que habilita a los ciudadanos a revocar el mandato de aquellas personas elegidas por voto popular que han dejado de contar con su aprobación y confianza. Somete a los funcionarios a la rendición de cuentas ${ }^{5}$.

Los procedimientos varían en alto grado, pero en general se canaliza a partir de un referéndum de revocación, el cual habilita a que la continuidad de los funcionarios investidos a través del voto ciudadano pueda ser puesta a consideración popular también por medio del voto.

En el marco de una democracia que incorpora instituciones de tipo "directas", su principal función es la de habilitar una participación ciudadana "negativa" o de control, más que de expresión o gestión "positiva" de proyectos e iniciativas ciudadanas, ya que supone rescindir el contrato de representación erigido por el voto antes de que expire el período preestablecido.

Constituye por tanto un instrumento de accountability, entendida como la capacidad para asegurar que los funcionarios públicos rindan cuentas por sus actos y omisiones, la facultad de obligarlos a justificar y a informar sobre sus decisiones y la disponibilidad para que eventualmente puedan ser castigados por ellas ${ }^{6}$. Esto implicaría una rendición obligatoria de cuentas ${ }^{7}$. No una concesión generosa realizada por los representantes, sino un acto compulsivo y propicio en democracia.

Específicamente, se trata de un instrumento de accountability vertical. Esto es, un control que surge desde la sociedad civil y se dirige hacia los representantes del gobierno (de abajo hacia arriba o down top), a diferencia de la accountability horizontal, interna al aparato estatal o ejercida entre sus diferentes poderes instituidos: Ejecutivo, Legislativo, Judicial ${ }^{8}$. Dentro de la dimensión vertical, funcionaría asimismo como un mecanismo de accountability societal. Es decir, un control vertical no electoral ${ }^{9}$ de las autoridades políticas.

\footnotetext{
5 CRONIN, Thomas. Direct Democracy. The Politics of Initiative, Referéndum and Recall. Cambridge: Harvard University Press, 1989. p. 145.

6 Smulovitz, Catalina. Judicialización y Accountability Social en Argentina. XXII International Conference. Washington: Latin American Studies Association, 2001. p. 2.

7 SCHEDLER, Andreas. Conceptualizing accountability. En SCHEDLER, Andreas; DIAMOND, Larry y PLATTNER, Marc. The self-refraining State: power and accountability in new democracies. London: Lynne Rienner Publishers, 1999.

8 O`DONNELL, Guillermo. Accountability horizontal: la institucionalización legal de la desconfianza política. Revista Española de Ciencia Política, Madrid, n. 11, p. 11-31, oct. 2004.

9 La accountability vertical electoral es que la que ejerce la ciudadanía cuando finaliza el mandato preestablecido de un representante $y$, a través de su voto, puede premiarlo por su gestión al elegirlo para un nuevo período (a él o a un copartidario) o castigarlo no renovándole la banca (a él o a un copartidario).
} 
La otra forma de revocatoria existente en Panamá es bastante más novedosa y, a la vez, polémica. Se trata de la revocatoria partidaria, popularmente conocida como "anti-tránsfuga", dispuesta para ser empleada contra quienes "huyen de una parte a otra"10. Consiste en un mecanismo de control y sanción intra-partidaria que fomenta la disciplina de los diputados y demás representantes para que se mantengan en línea con y bajo las órdenes de los líderes del partido por el cual fueron elegidos. Asimismo, pretende desalentar las rupturas de bloque y el traspaso a otra agrupación política una vez asumido el cargo.

La adopción de esta modalidad generó inicialmente en el país una gran discusión entre los partidos y una fuerte oposición en la sociedad civil, que consideraba que únicamente el pueblo que elegía a un diputado podía revocarlo (y no así los partidos). Este punto era clave en la discusión respecto de la representación política y la democracia.

Sus detractores ponían de relieve que el legislador, al igual que todos los funcionarios electos a través del voto popular, debía su elección a la comunidad de sufragantes: el electorado. Los partidos eran solo los proponentes de la candidatura, que el pueblo aprobaba o rechazaba con sus votos. Restringido su ámbito al de la presentación de candidaturas, el partido estaba usurpando con este mecanismo una facultad que le concernía única y exclusivamente a la voluntad libre e incoercible del pueblo soberano, por encima de banderías ideológicas. Se la acusaba de instaurar una "dictadura de partidos" que imponía consignas y directivas al legislador, aniquilando su capacidad de discernimiento político y ordenándole cómo actuar y cómo votar en cada coyuntura.

Lo anterior no negaba el hecho de que en algunas ocasiones el legislador podía estar actuando en desacuerdo con los principios ideológicos y con independencia programática al votar en contra de la línea del partido, "guiado ilícitamente por escondidos y subalternos motivos de ventajismo personal"11. Sin embargo, en tales casos, que tipificaban conductas delictivas, sus críticos argumentaban que procedía la denuncia penal con acompañamiento de pruebas fehacientes ante las autoridades competentes. Advertían que si bien no se debía confundir principios con intereses materiales individuales, la revocatoria de mandato como sanción de cualquier partido (de oposición o de gobierno), a espaldas de la voluntad de los electores, era un ultraje antidemocrático que ofendía la vocación de libertad del pueblo panameño.

No obstante, como la modalidad partidaria contempló la posibilidad de que los partidos incluyeran en sus estatutos una instancia previa de consulta popular, los

10 [s.a.]. Ley antitránsfugas, a tercer debate. La Estrella de Panamá, Panamá, ene. 2013. Disponible en: <http://laestrella.com.pa/panama/politica/antitransfugas-tercer-debate/23469726>. Acceso en: 12 dic. 2018.

11 [s.a.]. Ley antitránsfugas, a tercer debate. La Estrella de Panamá, Panamá, ene. 2013. Disponible en: <http://laestrella.com.pa/panama/politica/antitransfugas-tercer-debate/23469726>. Acceso en: 12 dic. 2018. 
reclamos fueron relativizados al concederse también a la ciudadanía la facultad de opinar sobre la decisión partidaria de revocar el mandato a sus representantes.

\section{REVOCATORIA POPULAR Y REVOCATORIA PARTIDARIA EN PA- NAMÁ: LA NORMATIVA}

\subsection{La Constitución Política de la República de Panamá, 11 de octu- bre de 1972}

En Panamá, la revocatoria de mandato "popular", o iniciada por la ciudadanía, se incluyó por primera vez en una Constitución nacional en el año $1972^{12}$, donde se la contemplaba en forma incipiente como una de las causas de pérdida de la representación de los representantes de corregimiento (miembros de los consejos municipales), junto con el cambio voluntario de residencia a otro corregimiento y la condena judicial fundada en delito (art. 134\%). En caso de quedar vacante la representación de corregimiento se preveía la celebración de elecciones dentro de los dos meses subsiguientes para elegir nuevos Representantes (art. 135\%).

\subsection{La Ley № 19, 9 de julio de 1980}

La Ley que reglamentó el artículo constitucional $134^{\circ}$ referido a la pérdida de representación fue la № $19^{13}$, de 1980. El artículo $1^{\circ}$ estipula que los representantes de corregimiento pierden su representación por el cambio voluntario de residencia fuera del corregimiento, la condena judicial fundada en delito, la revocatoria de mandato $y$, como agregado, la renuncia.

En cuanto a la revocatoria, el artículo $17^{\circ}$ de esta ley postula además que, cuando a juicio de la comunidad un representante haya ocasionado un perjuicio notorio a los intereses del corregimiento, los ciudadanos allí residentes tienen el derecho de solicitar la revocatoria de mandato. Para efectuar la solicitud, los ciudadanos residentes en el corregimiento, en número equivalente a, como mínimo, el 75\% de la población electoral, deben presentarse a firmar personalmente el pedido ante el Tribunal competente.

Cabe destacar lo extremadamente alto que resulta el piso de avales requerido para iniciar el mecanismo (tres cuartas partes del padrón), y que son los propios ciudadanos los que deben acercarse voluntariamente a firmar (en lugar de habilitar a algún

\footnotetext{
12 PANAMÁ. Constitución Política de la República de Panamá de 1972. Disponible en: <http://200.46.254.138/ legispan/PDF_NORMAS/1970/1972/1972_028_2256.PDF>. Acceso en: 4 may. 2018.

13 PANAMÁ. Ley no 19 de 1980. Por la cual se deroga la Ley 6 del 10/02/1978 y se dictan disposiciones sobre la pérdida de representación ejercida por el representante de corregimiento y el suplente. Disponible en: <http:// docs.panama.justia.com/federales/leyes/19-de-1980-jul-15-1980.pdf>. Acceso el: 4 may. 2018.
} 
promotor que se encargue de la recolección en puntos cercanos a los domicilios de los votantes). Ambas prescripciones hacen prácticamente imposible la presentación exitosa de una solicitud.

El artículo $18^{\circ}$ excluye al primer y último año de ejercicio del cargo de representante de corregimiento de la posibilidad de solicitud de revocatoria, y el artículo $19^{\circ}$ aclara que la revocatoria del mandato del principal conlleva la del suplente.

Una vez reunidas las firmas requeridas en el artículo 170 "y oído el concepto del Fiscal ·Electoral", el Tribunal Electoral (TE) debe convocar a plebiscito a los ciudadanos del respectivo corregimiento para determinar si aprueban o no la revocatoria (art. $20^{\circ}$ ). Dicho Tribunal debe reglamentar la celebración del plebiscito. También le compete actualizar el Registro Electoral del corregimiento al momento de convocar al plebiscito (art. 210).

Finalmente, la representación se considera revocada si en el plebiscito votan a favor de la destitución por lo menos el 75\% de los ciudadanos empadronados en el Censo Electoral del corregimiento (art. 22\%). Esta exigencia excesivamente elevada de votos favorables a la revocación (no solo deben votar las tres cuartas partes del total de los electores hábiles sino que además todos ellos deben hacerlo afirmativamente), sumada al muy alto piso de avales exigidos en la solicitud, convertían a la revocatoria en una meta imposible de alcanzar.

Un punto importante surge respecto del reemplazo del principal y suplente revocados: el TE debe convocar a elecciones parciales a fin de cubrir ambos cargos, las que deben celebrarse dentro de los dos meses siguientes a la fecha de la declaratoria de la pérdida de la representación (art. 24º). Como sostiene Valdés Escofferry ${ }^{14}$ sobre dicha normativa: "obviamente, con requisitos tan exigentes, la Ley no se ha aplicado en ningún caso".

\subsection{Constitución Política de la República de Panamá de 1972 con re- formas de 1978 y 1983, 4 de mayo de 1983}

La reforma constitucional de $1983^{15}$, en su artículo $145^{\circ}$, incorporó a la revocatoria partidaria o ejercida a través de los partidos. En adelante, estos podrían revocar el mandato de los legisladores titulares o suplentes que hubieran postulado. Esta modalidad introduce una novedad por no activarse a partir de una iniciativa popular ni mediar el voto de la población en referéndum, dejando por tanto de pertenecer a la clasificación de mecanismo de "democracia directa".

\footnotetext{
14 Valdés Escofferry, Eduardo. Reforma electoral en América Latina: el caso Panamá. In: Zovatto, Daniel y Orozco Henríquez, Jesús. Reforma política y electoral en América Latina. Serie Doctrina Jurídica n 418. México: Unam-IDEA Internacional, 2008. p. 726.

15 PANAMÁ. Constitución Política de la República de Panamá de 1972, con reformas de 1978 y 1983 . Disponible en: <http://bdigital.binal.ac.pa/bdp/const/Constitucion197283.pdf>. Acceso en: 15 sep. 2018.
} 
Sin perder su cualidad de herramienta de destitución anticipada de representantes por vías institucionales, no conforma sin embargo un mecanismo de participación y control ciudadano propiamente dicho, ya que se ejecuta por iniciativa exclusiva del partido que postuló al candidato y según las causas y formas establecidas en su estatuto.

Para que los partidos pudieran ejecutar este mecanismo respecto de los representantes por ellos postulados, debían cumplirse los siguientes requisitos y formalidades: que las causales de revocatoria y el procedimiento aplicable estuviesen previstos en los Estatutos de Partido; que tales causales se refirieran a violaciones graves de los Estatutos y de la plataforma ideológica, política o programática del partido y que hubiesen sido aprobadas mediante resolución dictada por el TE con anterioridad a la fecha de postulación; que se garantizare el derecho del afectado, dentro de su Partido, a ser oído y a defenderse en dos instancias; y que la decisión del partido en que se adoptase la revocatoria estuviese sujeta a recurso del cual conocería privativamente el TE y tendría efecto suspensivo.

En esta modalidad de revocatoria cada partido conserva la potestad de adoptarla (o no), pero, para que pueda emplearla, debe estar primero incorporada en su Estatuto: “la revocatoria es opcional y (..) los partidos no están obligados a incorporarla en sus estatutos"16.

Finalmente la reforma constitucional de 1983 concede a los partidos el derecho de revocar el mandato a legisladores principales y suplentes que hubieran renunciado expresamente y por escrito a sus filas; mientras que el artículo $224^{\circ}$ enumera a la revocatoria de mandato (junto con el cambio voluntario de residencia a otro corregimiento y la condena judicial fundada en delito) como una de las causas de pérdida de la representación.

\subsection{Constitución Política de la República de Panamá, Acto Legislati- vo № 1, 27 de abril de 2004}

La reforma constitucional de $2004^{17}$ incorpora en forma plena el reconocimiento a los ciudadanos electores de un circuito electoral ${ }^{18}$ (vía solicitud al TE) del derecho a revocar el mandato de los diputados de libre postulación (independientes) que hubieran elegido (art. $151^{\circ}$ ). Esto es, la revocatoria popular. Aclara que a cada diputado

\footnotetext{
16 VALDÉS ESCOFFERRY, Eduardo. Reforma electoral en América Latina: el caso Panamá. In: Zovatto, Daniel y Orozco Henríquez, Jesús. Reforma política y electoral en América Latina. Serie Doctrina Jurídica nº 418. México: Unam-IDEA Internacional, 2008. p. 716.

17 PANAMÁ. Constitución Política de la República de Panamá. Acto Legislativo no 1 de 2004. Disponible en: <http://pdba.georgetown.edu/Constitutions/Panama/vigente.pdf>. Acceso en: 15 nov. 2018.

18 La Asamblea Nacional se compone de diputados elegidos por circuitos electorales uninominales y plurinominales (artículo $147^{\circ}$ de la CN).
} 
le corresponde un suplente personal elegido con el diputado principal el mismo día, quién lo reemplazará en sus faltas (art. $147^{\circ}$ ).

La introducción plena de la revocatoria popular no anula sino que se suma al derecho otorgado por la Constitución en 1983 a los partidos para revocar el mandato a diputados principales o suplentes que hubieran postulado (la revocatoria partidaria).

En el caso de revocatoria partidaria, se estipula ahora como requisito: que las causales de revocatoria y el procedimiento aplicable estén previstos en los estatutos del partido; que se refieran a violaciones graves de los estatutos y de la plataforma ideológica, política o programática; y/o que el legislador haya sido condenado por delito doloso con prisión de 5 años o más. Como contrapartida, concede al afectado el derecho a ser oído y a defenderse en su partido y sujeta a recurso la decisión de éste. Asimismo habilita a los partidos a establecer consultas populares con los electores del circuito, previo a iniciar el proceso, y a revocar el mandato de diputados por sumario cuando hayan renunciado al partido.

En esta reforma constitucional, la revocatoria alcanza también a los representantes de corregimiento (presidentes de las Juntas Comunales de los corregimientos). Puede ser motorizada por iniciativa popular o por los partidos cuando fueron postulados por estos. El artículo $227^{\circ}$ menciona a la revocatoria como uno de los motivos (junto con el cambio voluntario de residencia a otro Corregimiento y la condena judicial fundada en delito) de pérdida de la representación de esos gobernantes.

En síntesis, a partir de 2004 puede revocarse el mandato de representantes de corregimiento y de diputados de la Asamblea Nacional, tanto por parte de los ciudadanos como de los partidos, dependiendo de si los mandatarios fueron elegidos por libre postulación (directamente por la ciudadanía, como candidatos independientes) o si lo hicieron a través de su pertenencia partidaria. Por primera vez desde ese año, ambas modalidades de revocatoria conviven en la Constitución Nacional panameña.

\subsection{La Ley $\mathrm{N}^{\circ} 60$ Que reforma el Código Electoral, 29 de diciembre de 2006}

La primera Ley que reglamentó la revocatoria ampliada, esto es, de los diputados y representantes de corregimiento postulados por partidos y los de libre postulación, fue la $\mathrm{N}^{\circ} 60^{19}$ de 2006, que reforma el Código Electoral. En su artículo $15^{\circ}$ contempla el derecho de revocatoria partidaria cuando estipula que los estatutos de los partidos deben contener las causales de revocatoria y el procedimiento aplicable si fuera el caso.

El capítulo decimoquinto se dedica por entero a este mecanismo. Comienza en su Sección $1^{\text {a }}$ regulando la revocatoria del mandato de diputados postulados por los

19 PANAMÁ. Ley no 60 de 2006. Que reforma el Código Electoral. Disponible en: <http://docs.panama.justia. com/federales/leyes/60-de-2006-jan-2-2007.pdf>. Acceso el: 15 nov. 2018. 
partidos (revocatoria partidaria). El artículo $328^{\circ} \mathrm{A}$ dice que el partido político al que se le haya adjudicado la curul podrá revocar el mandato del diputado principal o suplente que haya postulado, inscrito o no en el partido, en casos de violación grave de los estatutos y plataforma ideológica o programática del partido, para lo cual las causales deben estar descritas en los estatutos y haber sido aprobadas por el TE con antelación a la fecha de postulación; por renuncia al partido; o por haber sido condenado por delito doloso, mediante sentencia ejecutoriada con pena privativa de libertad de 5 años o más. Respecto de esta última causal, resulta difícil entender cuál sería el valor agregado de la revocatoria luego de que hubiera actuado la justicia emitiendo una condena que de por sí sola merece el alejamiento automático del cargo.

La primera ocasión mencionada limita en cierta medida la arbitrariedad del partido al momento de ejercer el derecho de revocatoria, al exigir que las causales se encuentren detalladas en su estatuto, las que primero deben haber sido analizadas y aprobadas por la autoridad electoral, y luego dadas a conocer antes de la postulación del candidato.

Continuando con lo anterior, el artículo $328^{\circ} \mathrm{B}$ estipula que en sus estatutos los partidos deben indicar la autoridad que conocerá de los procesos de revocatoria y el procedimiento a seguir, garantizando la doble instancia interna de defensa al diputado. Constituye esta otra disposición que intenta establecer ciertos parámetros y límites a la decisión partidaria de revocar el mandato de uno de sus funcionarios electos.

El artículo $328^{\circ} \mathrm{C}$ concede al diputado principal o suplente afectado otra posibilidad de defensa. Agotadas las instancias y procedimientos internos al partido este puede impugnar la decisión ante el TE dentro de los siguientes 10 días hábiles. Dicha impugnación suspende los efectos de la decisión del partido.

Finalmente, se permite a los partidos establecer en sus estatutos el mecanismo de Consulta Popular reconocido en la Constitución (art. 328 D). Este mecanismo es opcional y puede usarlo el partido para legitimar popularmente su decisión de revocar a un representante elegido por la ciudadanía a través de su postulación partidaria, o para conocer la opinión popular sobre su voluntad de revocarlo antes de destituirlo por el procedimiento estatutario.

La Sección $2^{\text {a }}$ reglamenta la revocatoria de diputados electos por libre postulación (revocatoria popular). Las causales de pérdida del mandato son: el cambio voluntario de la residencia electoral fuera del circuito donde fue electo; la condena por delito doloso, mediante sentencia ejecutoriada, con pena privativa de la libertad de 5 o más años; y la decisión de los electores del circuito, mediante un referéndum revocatorio.

Los procesos de revocatoria que responden a las dos primeras causales, son iniciados por denuncia o de oficio por la Fiscalía General Electoral. Mientras que la tercera causal implica el mecanismo de revocatoria en su versión más clásica: promovida por iniciativa popular y efectivizada a través del voto por SI o NO de los ciudadanos. En esta 
última modalidad se excluye al primer y último año de mandato de la posibilidad de ser afectados por el inicio de estos procesos (art. $328^{\circ} \mathrm{E}$ ).

Para solicitar la revocatoria de mandato de un diputado principal o suplente de libre postulación según la modalidad correspondiente a la tercera causal (decisión de los electores), se requiere la firma del $30 \%$ de los ciudadanos que conformaban el Padrón del circuito al momento de su elección. El procedimiento debe ser reglamentado por el TE (art. $\left.328^{\circ} \mathrm{F}\right)$. Cumplido el procedimiento, dicho Tribunal debe convocar, en no más de 3 meses, a un referéndum, para determinar si se aprueba o no la revocatoria (art. $328^{\circ} \mathrm{G}$ ).

El mandato del diputado principal o suplente de libre postulación será revocado solo si en el referéndum la mayoría de los votos válidos son afirmativos (a favor de la destitución) y siempre que asista a votar un mínimo del $50 \%$ del Padrón del circuito (art. 328H).

La Sección $3^{a}$ se encarga de la pérdida de la representación y revocatoria de mandato de los representantes de corregimiento postulados por partido político (revocatoria partidaria) y los electos por libre postulación (revocatoria popular). El artículo $328^{\circ}$ I considera a la revocatoria del mandato como una de las causas de pérdida del cargo de representante de corregimiento. Las otras causales son: la condena judicial fundada en delito (el TE declara la vacancia del cargo mediante resolución motivada y a pedido de la Fiscalía General Electoral) y el cambio voluntario de residencia fuera de la circunscripción donde fue electo.

Asimismo, detalla los casos en los que aplica revocatoria. Si fue postulado por un partido (esté o no inscrito en él): por violación grave de los estatutos (siempre que las causas estén previstas en ellos, con previa aprobación del TE, indicándose la autoridad a cargo y el procedimiento a seguir, garantizando la doble instancia y pudiendo establecer la consulta a los electores), por renuncia al partido, y por decisión de los electores de la circunscripción mediante un referéndum revocatorio. Si fue electo como candidato de libre postulación, por decisión de los electores de la circunscripción, mediante un referéndum revocatorio convocado al efecto. La revocatoria de mandato por iniciativa popular no puede iniciarse durante el primer y último año del cargo (art. 328이).

Cabe aquí hacer notar que la decisión de los electores de la circunscripción de convocar a referéndum revocatorio por su propia iniciativa se aplica tanto a los representantes de corregimiento que han sido postulados por un partido como a los de libre postulación. En cambio, el partido político solo tiene derecho de revocar el cargo de un funcionario en caso de que este haya sido postulado a través suyo y haya incurrido en alguna de las causales arriba mencionadas estando estipuladas en los estatutos.

Para los representantes de corregimiento postulados por un partido que hayan incurrido en la primera causal de revocatoria (la violación grave de los estatutos), el artículo $328^{\circ} \mathrm{J}$ prevé que, agotadas las instancias y procedimientos internos al partido, el 
mandatario puede impugnar la decisión ante el TE dentro de los 10 días hábiles siguientes a la ejecutoria. La impugnación suspende los efectos de la decisión del partido.

El artículo $328^{\circ} \mathrm{K}$ postula como requisito para solicitar una revocatoria de un representante de corregimiento por iniciativa popular, recolectar la firma del $30 \%$ de los ciudadanos registrados en el padrón de la circunscripción, siendo el procedimiento reglado por el TE. Una vez cumplido dicho paso, el Tribunal convocará a referéndum para ver si se aprueba o no la revocatoria. Este órgano electoral es el encargado de reglamentar la celebración de esa consulta (art. 328으). El mandato resulta revocado si la mayoría de los votos válidos emitidos en el referéndum resulta afirmativos (art. 328M). Acto seguido, la Fiscalía General Electoral debe solicitar ante el TE que se declare, mediante resolución motivada, la vacante del cargo de representante de corregimiento (art. $328^{\circ} \mathrm{O}$ ), con fundamento en el mencionado artículo 328이.

Es menester resaltar que la revocatoria del cargo de un representante de corregimiento postulado por un partido, que ha sido encausada por su propia agrupación, ofrece más garantías e instancias de defensa del cargo por parte del funcionario afectado (tanto internas como externas al partido) que aquella que es solicitada por iniciativa popular (de cumplimiento inmediato, en caso de reunirse las firmas y votos necesarios para ello).

Asimismo, a la primera modalidad de revocatoria, la ejecutada por el partido, se le exige enmarcarse dentro de alguna de las causas predeterminadas por la normativa, la que además debe ser especificada en los estatutos partidarios; mientras que a los electores de la circunscripción no se les delimita ni exige la presentación de causales, sino, en cambio, un número mínimo de apoyos (ciertamente elevado).

El mecanismo de revocatoria iniciada por el partido se asemeja más a un procedimiento de tipo judicial o controvertido entre partes que a un mecanismo de democracia directa, formato este último que sí adopta la revocatoria impulsada por iniciativa popular.

\subsection{La Ley $\mathbf{N}^{\circ} \mathbf{1 4}$ del $\mathbf{1 3}$ de abril de $\mathbf{2 0 1 0}$}

La reforma al Código Electoral realizada a través de la Ley $\mathrm{N}^{\circ} 14^{20}$ del 13 de abril de 2010, que rigió hasta el 30 de junio de 2014, entre otras cuestiones pretendió desarrollar el artículo $151^{\circ}$ inc. 4 de la Constitución Política sobre los requisitos y formalidades exigidos a los partidos para revocar los mandatos de los diputados titulares o suplentes que hubieran postulado. Específicamente, la disposición según la cual el afectado tendría derecho, dentro de su partido, a ser oído y a defenderse en dos instancias.

20 PANAMÁ. Ley nº 14 de 2010. Que dicta medidas sobre el certificado de información de antecedentes personales, reforma el Código Electoral y adiciona un artículo al Código Penal. Disponible en: <http://docs.panama. justia.com/federales/leyes/14-de-2010-apr-13-2010.pdf>. Acceso en: 4 may. 2018. 
Así, el artículo $3^{\circ}$ dispuso que la doble instancia a lo interno del partido se llevaría a cabo primero ante el Directorio Nacional, en el que se exigía que la decisión fuera unánime, y en segunda instancia ante el Congreso o Convención Nacional, donde la decisión requería el apoyo de las dos terceras partes de sus miembros. Estos organismos partidarios debían atender la revocatoria en sus sesiones ordinarias. Luego, para que la decisión del Congreso o Convención Nacional se perfeccionase, debía someterse a consulta de los electores del circuito correspondiente y ser aprobada por el voto de las dos terceras partes del padrón. Estos nuevos requisitos, de aprobación unánime y por 2/3 en los diferentes organismos internos al partido, y luego por 2/3 del electorado, hacía aún más complicado revocar el mandato a los diputados cuestionados por la agrupación.

En el mismo artículo se incluía la obligatoriedad para los partidos que adoptasen este mecanismo de establecer dicho procedimiento en sus estatutos para aplicarlo a la revocatoria de los diputados. Por último, el artículo $4^{\circ}$ adicionó el cargo de representante de corregimiento principal o suplente a su posible pérdida del mandato por revocatoria partidaria, debiendo también aplicarse el procedimiento previsto en el artículo anterior, el cuál debía incluirse en los respectivos estatutos.

\subsection{La Ley $\mathbf{N}^{\circ}$ 4, 7 de febrero de $\mathbf{2 0 1 3}$}

Posteriormente, se aprobó la ley que hasta la fecha de finalización de este trabajo regula su ejercicio, la $\mathrm{N}^{\circ} 4^{21}$ (conocida como "ley anti-tránsfuga"), promulgada por el entonces presidente de la república Ricardo Martinelli el 7 de febrero de 2013, y vigente desde el 1 de julio de $2014^{22}$ (art. 10). Esta normativa reforma y restablece algunos de los artículos del Código Electoral referidos a la revocatoria (manteniendo vigentes el resto de ellos). Para comenzar, postula que en los estatutos de los partidos se debe indicar la autoridad que conocerá del proceso de revocatoria de mandato de los diputados y el procedimiento a seguir, garantizando la doble instancia (art. $1^{\circ}$ ).

En el artículo $2^{\circ}$ menciona también que el cargo de representante de corregimiento, principal o suplente, se pierde (entre otras causales) por revocatoria de mandato. Si fue postulado por un partido, esté o no inscrito en él, las causas de revocatoria son, en primer lugar, la violación grave a los estatutos del partido, siempre que las causas estén previstas en los estatutos, hayan sido aprobadas previamente por el TE y se indique la autoridad que conocerá del proceso y el procedimiento a seguir, garantizando

21 PANAMÁ. Ley no 4 de 2013. Que reforma y restablece artículos del Código Electoral sobre la Revocatoria de Mandato, y dicta otra disposición. Disponible en: <http://www.organojudicial.gob.pa/cendoj/wp-content/ blogs.dir/cendoj/wdatj8b3ip-ley-4-de-7-de-febrero-de-2013.pdf>. Acceso el: 5 may. 2018.

22 [s.a.] Presidente Martinelli sanciona y promulgan Ley 4 de revocatoria de mandato. La Estrella de Panamá, Panamá, feb. 2013. Disponible en: <http://laestrella.com.pa/panama/politica/presidente-martinelli-sanciona-promulgan-4-revocatoria-mandato/23471610>. Acceso en: 3 oct. 2018. 
la doble instancia y pudiendo los partidos establecer mecanismos de consultas a los electores de la circunscripción para la aplicación de la revocatoria.

Si bien los partidos tienen la potestad de revocar el mandato de su representante, como quién otorga el cargo a través del voto es el pueblo, pueden preguntar antes a la ciudadanía, mediante el procedimiento de consulta popular, si está de acuerdo con dicha revocatoria. De este modo el partido podría corregir el rumbo o, en caso de destituirlo, la decisión partidaria no resultaría del todo cerrada o sin legitimidad popular.

Otra de las causales de revocatoria a representantes de corregimiento postulados por el partido es la renuncia a éste. Estas dos primeras causales estarían sustentando la revocatoria partidaria o ejecutada por el partido de pertenencia del mandatario.

La tercera causa para revocar a un representante de corregimiento postulado por un partido es la decisión de los electores de la circunscripción mediante referéndum revocatorio (revocatoria popular). Con lo cual, los representantes de corregimiento que han sido elegidos a través de la postulación partidaria pueden no obstante también ser revocados directamente por iniciativa ciudadana, incluso cuando el partido no esté de acuerdo. Se pone de manifiesto una suerte de "doble pertenencia" del cargo postulado por un partido en Panamá: le "pertenece" al propio partido que postuló al candidato y a la población que lo eligió, motivo por el cual cualquiera de estas dos fuentes de legitimidad puede también revocarlo.

La pérdida del cargo de Representante de corregimiento principal o suplente vía revocatoria de mandato también aplica para quienes fueron electos por libre postulación. Esta se ejecuta por decisión de los electores de la circunscripción, mediante referéndum revocatorio (revocatoria clásica o popular).

Al final del artículo $2^{\circ}$ sobre la pérdida del cargo por revocatoria se aclara que no se podrán iniciar procesos revocatorios por iniciativa popular durante el primer y último año de ejercicio. De este modo se tendería a evitar que la revocatoria se iniciara por motivos de especulación electoral: la exclusión del primer año de mandato permite que el funcionario ejecute su plan de gobierno por el lapso de 12 meses. Antes de ese tiempo, sería posiblemente apresurado emitir un juicio fundado sobre su gestión. Por su parte, la exclusión del último año evita que la expectativa de un año electoral estimule una salida y reemplazo anticipado del mandatario por pura especulación política, o que se su salida se adelante solo unos pocos meses multiplicando inútilmente los costos de votación. Tratándose de cargos de 5 años de duración, el período plausible de revocatoria en este país supera la mitad del mandato, elevándose a tres años.

En cuanto a la causal referida a la violación de los estatutos partidarios, el artículo $3^{\circ}$ otorga al representante de corregimiento afectado, una vez agotadas las instancias y procedimientos en lo interno del partido, el derecho de impugnar la decisión ante el TE dentro de los 10 días hábiles siguientes a la ejecutoria, suspendiendo con ello los efectos de la decisión del partido. Cabe hacer notar que la revocatoria perpetrada 
por el partido bajo la causal de violación de estatutos tiene un resultado susceptible de ser impugnado ante el Tribunal y dejado sin efecto, mientras que la decisión de revocatoria por votación popular en referéndum arroja un resultado definitivo e incontestable ante el pronunciamiento ciudadano en las urnas.

Para solicitar la revocatoria a un representante de corregimiento por iniciativa popular se exige la firma del $30 \%$ de los ciudadanos empadronados en la circunscripción (art. $4^{\circ}$ ), un piso alto que protege su supervivencia en el cargo. Cumplido dicho procedimiento, el TE debe convocar a referéndum para ver si se aprueba o no la revocatoria (art. $5^{\circ}$ ). El mandato es revocado si en el referéndum la mayoría de los votos válidos resultan afirmativos (art. $6^{\circ}$ ).

Como novedad, se adiciona el artículo $376^{\circ} \mathrm{A}$ al Código Electoral, según el cual, lo anterior podrá ser igualmente aplicado para revocar el mandato a los alcaldes de distrito, tanto los que hayan sido electos por partidos o mediante libre postulación (art. $7^{\circ}$ ). Respecto del reemplazo de los funcionarios revocados, la versión completa de este Código Electoral $2013^{23}$, prevé la celebración de elecciones parciales cuando el cargo hubiera quedado vacante por ausencia absoluta del principal y el suplente, salvo que faltase menos de un año para que venciera el periodo (art. $352^{\circ}$ ).

\section{LA REVOCATORIA DE MANDATO EN LOS HECHOS}

En Panamá, hacia junio de 2014 el recall se había aplicado en forma completa y con resultado revocatorio solamente a dos diputados. Sin embargo, la modalidad empleada en ambos casos no fue la revocatoria de mandato concebida como un mecanismo de democracia directa (iniciado por la ciudadanía a modo de control de sus gobernantes), sino aquélla otra vía de destitución del representante cuya implementación correspondía enteramente al partido que lo postuló. A excepción del período 2010-julio de 2014 donde la consulta ciudadana fue por ley obligatoria para los partidos que desearen destituir a sus representantes, antes y después de dicha normativa esta vía les permitía prescindir de la participación ciudadana, a excepción de aquellos partidos que optasen por incluir en su procedimiento una instancia de consulta popular. A partir de la mencionada reforma de 2010, la percepción general era que, si bien el mecanismo había cobrado cierta vigencia, con esta modificación prácticamente se impedía su aplicación ${ }^{24}$.

\footnotetext{
23 PANAMÁ. Tribunal Electoral. Código Electoral 2013. Panamá. 2013. Disponible en http://www.tribunal-electoral.gob.pa/html/fileadmin/user_upload/publicaciones/CODIGO_ELECTORAL_01.pdf. Acceso el: 15 de julio de 2018.

24 BUSTAMANTE, Aminta. Revocatoria de mandato, una norma difícil de aplicar. Panamá América, Ciudad de Panamá, abr. 2012. Disponible en: <https://www.panamaamerica.com.pa/nacion/revocatoria-de-mandato-una-norma-dificil-de-aplicar-803861>. Acceso el: 23 nov. 2018.
} 
Los dos casos de revocatoria consumada fueron motorizados por el Partido Revolucionario Democrático (PRD) contra dos de sus diputados. En el primer caso, el legislador Mario Miller fue expulsado de las filas partidarias debido a las denuncias que pesaban en su contra por extorsión a empresarios. Luego, el partido lo destituyó del cargo según el procedimiento previsto en sus estatutos y sin mediación del voto ciudadano.

La decisión partidaria se fundamentó en el incidente del 22 de noviembre de 1994, en el que el legislador Miller había sido sorprendido por agentes de la policía en el momento en que presuntamente recibía un maletín con 100.000 dólares. El dinero era sospechado de conformar la paga de unos comerciantes que supuestamente habían sido extorsionados por el diputado. Miller resultó comprometido junto a un grupo de funcionarios copartícipes en el presunto acto de extorsión.

El 8 de diciembre, luego de un conflicto que había enfrentado al Parlamento panameño con el procurador Jorge Valdés, se retiró a Miller la inmunidad ${ }^{25}$. A pesar de esta decisión, el pleno del Parlamento señaló en una resolución que aunque existían indicios que ameritaban una investigación al diputado, todavía había dudas sobre la comisión del "in fraganti delito" atribuido.

En su defensa, el legislador adujo que todo había sido una encerrona para "liquidarlo políticamente", debido a que "andaba persiguiendo a los corruptos" del anterior gobierno ${ }^{26}$. En el mes de octubre anterior Miller había acusado a la esposa del ex presidente Guillermo Endara, Ana Mae Díaz, y al ex diputado Francisco Artola, del antiguo gobernante Partido Arnulfista, por presuntos actos de corrupción realizados con una partida de 10 millones de dólares que había sido otorgada por el gobierno para socorrer a las víctimas del terremoto de 1991. Hacia el 15 de noviembre, la fiscal que investigaba la demanda concluyó que existían méritos suficientes para procesar a Díaz de Endara y a Artola por el uso irregular de dichos fondos.

Sin embargo, a pesar de las dudas expresadas por el Parlamento sobre el in fraganti delito de Miller, el gobernante PRD expulsó al diputado de sus filas. En la Resolución del 7 de diciembre justificó su decisión por violación a los principios, programas, estatutos e intereses de la organización. Asimismo, el Tribunal de Honor del partido pidió a su Comisión Política que gestionara ante las autoridades electorales la revocatoria definitiva de la banca del diputado. El "caso Miller", que durante más de dos semanas mantuvo en vilo al Parlamento, a la Procuraduría y a la opinión pública, se convertiría en el primer suceso serio de presunta corrupción en los primeros cien días de gobierno del presidente Ernesto Pérez Balladares del PRD.

25 HERNÁNDEZ, Silvio. Panamá: Retiran inmunidad a diputado acusado de extorsión. Inter Press Service, [s.I.], 1994. Disponible en: <http://www.ipsnoticias.net/1994/12/msg076g01e-panama-retiran-inmunidad-a-diputado-acusado-de-extorsion >. Acceso el: 12 dic. 2018.

26 BUSTAMANTE, Aminta. Revocatoria de mandato, una norma difícil de aplicar. Panamá América, Ciudad de Panamá, abr. 2012. Disponible en: <https://www.panamaamerica.com.pa/nacion/revocatoria-de-mandato-una-norma-dificil-de-aplicar-803861>. Acceso el: 23 nov. 2018. 
El partido resolvió revocar el mandato del legislador y el TE lo avaló. Esta decisión partidaria fue adoptada antes de que culminara el proceso judicial y, según manifestó en forma expresa, se hizo con independencia de cuál pudiese ser su desenlace: el solo involucramiento en un caso delictivo semejante implicaba, a su juicio, una ofensa grave contra los principios del partido digna de expulsión.

El procedimiento revocatorio aplicado tuvo sus vaivenes y culminó con la Resolución No J-1/94 del 7 de diciembre en el que el Tribunal partidario decidió: que la conducta ciudadana y política del legislador miembro del PRD antes y durante los hechos públicos y notorios en que se vio involucrado resultaba manifiestamente contraria a los principios del partido; que la misma no era apropiada a los lineamientos acordados por los órganos rectores del Partido, que sustentaron la oferta política en la campaña y que debían servir de guía y ser respetados por todo miembro del partido que ocupase un cargo de elección popular; que su conducta quedaba tipificada como causal de expulsión del partido según las normas estatutarias y reglamentarias vigentes; y que Mario Miller quedaba sujeto a la revocatoria de mandato como legislador del PRD por haber incurrido en causal establecida en los estatutos.

El Tribunal partidario decidió la expulsión de Miller como miembro del PRD y adelantó lo necesario para la revocatoria de su mandato como legislador del partido. Por último se comunicó esa Resolución al TE y a la Asamblea Legislativa para que fuera ejecutoriada.

El afectado apeló la decisión partidaria presentando un recurso de impugnación contra las resoluciones J-1/94 del 7 de diciembre, dictada por el Tribunal de Honor y Disciplina del partido, y la 01-95 del 4 de marzo, expedida por la Comisión Política del partido ${ }^{27}$. El demandante solicitaba que el TE revocase ambas resoluciones, violatorias de los estatutos, la legislación y la Constitución política.

El apoderado del PRD negó las aludidas violaciones procedimentales y aclaró que la Comisión Política del partido no había fundamentado su decisión sólo en una supuesta conducta penal del legislador políticamente censurable, sino en las faltas cometidas contra los estatutos y principios fundamentales del PRD, que consagraban (entre muchas otras cosas), el logro de una sociedad moral y patrióticamente fortalecida en la que se consolidasen y desarrollasen valores de equidad, confraternidad y solidaridad humana.

El 24 de abril se celebró una nueva audiencia donde se escuchó el alegato de las partes. Aún así, finalmente se mantuvo la decisión inicial del Tribunal de Honor y Disciplina del PRD de expulsarlo del partido. El 22 de mayo el TE ratificó que el Tribunal de Honor podía decidir en primera instancia tanto la expulsión como la revocatoria de

27 PANAMÁ. Tribunal Electoral. Impugnación contra las resoluciones J-1/94 fechada 7/12/1994 y la 01-95 fechada 4/03/1995, dictadas por el PRD. Panamá. 1995. Disponible en: http://www.oas.org/sap/docs/DECO/ legislacion/pa/Reparto\%203-1995-ADM.pdf. Acceso el: 25 de agosto de 2018. 
mandato del legislador o imponer cualquiera de ambas sanciones sin la otra. Ninguna disposición prohibía tal cosa al partido, aunque se recomendaba su especificación en los estatutos.

Por otro lado, en cuanto a las causales invocadas para la revocatoria, el TE debía ahora determinar si las mismas constituían violaciones graves a los estatutos y de la plataforma ideológica, política o programática del PRD según lo exigido por el ordinal $2^{\circ}$ del artículo $145^{\circ}$ de la Constitución. Para ello tomó en cuenta lo que el partido había aducido como causal de expulsión y revocatoria del mandato.

EI TE valoró que para el CEN del PRD el sólo hecho de que un legislador estuviera involucrado en la comisión de un delito de extorsión, con la cantidad de indicios que existían en su contra, independientemente de que resultara o no condenado penalmente por ello, constituía una violación grave a los estatutos y plataformas del partido que justificaba la pérdida del curul como legislador y que esa persona no permaneciera ni continuara en la Asamblea Legislativa representando al partido ni al pueblo.

Asimismo, ratificó la prerrogativa casi exclusiva del Partido de decidir si la conducta de un legislador era incompatible con el ejercicio de un curul legislativo, al tenor de los compromisos asumidos con este por mandato de los estatutos. Finalmente coincidió con el partido en que era vital para la democracia que todos los partidos se esforzaran por mantener una imagen de seriedad y transparencia, de respeto y cumplimiento de las normas legales y estatutarias y que sus legisladores honrasen con cabalidad esa imagen, manteniéndose totalmente al margen de acontecimientos delictivos. Exponerse a éstos era exponer su curul; exponerse a quedar involucrados era exponerse a la pérdida del cargo.

Dicha exposición por parte del legislador fue interpretada por el TE como una violación grave a los estatutos y plataformas del PRD, que ameritaba la acción adoptada por este. Si bien aclaró que ello no implicaba un adelantamiento de juicio respecto de la responsabilidad penal del legislador ni pasaba por alto la presunción de inocencia, sí ratificaba la medida disciplinaria del partido, impuesta no por la comisión del delito sino por el involucramiento en él siendo legislador de la República, más allá de ser luego hallado culpable o inocente. De este modo, el TE ratificó como válido lo actuado por el PRD, confirmando en todas sus partes sus resoluciones, en el sentido de revocar el mandato de Miller como legislador del Circuito 1-1.

EI TE ratificó, con su Sentencia del 22 de mayo, la revocatoria de Miller ejecutada por el PRD, la que no admitía recurso en contra. Si bien Miller reclamó su derecho a la presunción de inocencia y a un debido proceso de justicia ordinaria, y denunció haber sido víctima de un procedimiento apresurado que influyó negativamente en su curso; no pudo evitar ser el primer representante expulsado de su partido y cuyo cargo fue revocado. Luego se lo condenó a 44 meses de prisión por extorsión y asociación ilícita 
para delinquir. En el año 2000, tras haber pasado un tiempo en la cárcel, la Corte Suprema de Justicia decidió revocar su condena ${ }^{28}$.

El otro caso de revocatoria que tuvo lugar en Panamá también fue de tipo partidaria y ocurrió en el período legislativo 1999-2004. El legislador santeño Carlos 'Tito' Afú afrontó la expulsión del PRD y la revocatoria de su mandato.

A fines de 2001 el partido inició un proceso en su contra, acusándolo de haber desafiado los lineamientos partidarios por haber votado a favor de la ratificación de Alberto Cigarruista y de Winston Spadafora como magistrados de la Corte Suprema de Justicia. Spadafora había sido Ministro del Interior de la entonces presidente Mireya Moscoso del Partido Panameñista, que gobernó durante ese período (1999-2004). También se le endilgó haber aceptado coimas del gobierno de Moscoso a cambio de su apoyo.

Afú contestó, primero, acusando a su partido de haber aceptado gratificaciones "en masa" del consorcio San Lorenzo, un contratista de la construcción. Segundo, inició una impugnación, Reparto 10-2002-ADM, contra las resoluciones revocatorias del 19 de diciembre de 2001 y la № 10 del 4 de enero de 2002, ambas expedidas por el Consejo Directivo Nacional (CDN) del PRD.

El 22 de abril de 2002 presentó una nueva impugnación fundamentada en que dichas Resoluciones impugnadas habían creado una nueva causal de expulsión del partido y de revocatoria que no estaba previamente establecida y aprobada por Resolución del TE.

En esa demanda de impugnación incluyó además una Advertencia de Inconstitucionalidad respecto de las reformas a los Estatutos, Principios y Programas del PRD, que habían sido aprobados por el TE mediante Resolución № 245, de fecha 16 de agosto de 1995, y № 295, del 17 de octubre de 2001. Se advertía que los artículos 83, 102, $103^{\circ}$ de los Estatutos del PRD y la reforma № 77 contenida en las mencionadas resoluciones, en lo referente a la expulsión del partido y revocatoria de mandato de legisladores de la Asamblea, violaban los artículos $37^{\circ}, 43^{\circ}, 144^{\circ}, 145^{\circ}, 148^{\circ}$ y cualquier otro de la Constitución de conformidad con el artículo $203^{\circ}$ de ella, el artículo $2.558^{\circ}$ del Código Judicial, el artículo $92^{\circ}$ del Código Electoral y el $2^{\circ}$ de los Estatutos del partido ${ }^{29}$.

Independientemente de cuál fuese el resultado del proceso disciplinario que se le adelantaba a nivel de su partido, Afú tenía derecho a recurrir al TE ${ }^{30}$. Correspondería

\footnotetext{
28 RODRÍGUEZ, Ivonne. Los doce casos más importantes de la historia democrática. La Estrella de Panamá, jun. 2014. Disponible en: <http://laestrella.com.pa/panama/politica/doce-casos-importantes-historia-democratica/23779514>. Acceso el: 3 may. 2018.

29 PANAMÁ. Tribunal Electoral. Reparto 10-2002-ADM. Panamá. 2005. Disponible en: http://201.174.39.184/ Fallos_Relevantes/10_2002.pdf. Acceso el: 15 de mayo de 2018.

30 Gálvez F., Florencio. Caso de Afú podría llegar a la Corte. Portal Crítica, mar. 2002. Disponible en: <http:// portal.critica.com.pa/archivo/03212002/nac09.html>. Acceso el: 16 ene. 2019.
} 
luego a ese órgano determinar sobre la legalidad o no del proceso seguido dentro del PRD, siempre que hubieran transcurrido las dos instancias previas reglamentarias.

Lo anterior no prevenía o impedía que pudiera haber también un pronunciamiento de la Corte Suprema de Justicia si se demandaba por inconstitucionalidad el proceso o el acto mismo que había dispuesto la revocatoria de mandato. Ello, debido a que para algunos funcionarios y ex funcionarios, el hecho de que un legislador votara por determinado candidato a magistrado no era causal de revocatoria de mandato: "Votar por Pedro o por María no implica que el legislador este violando normas de la ideología o de la plataforma de gobierno o su programa" ${ }^{31}$.

Luego vendría el Reparto 11-2002-ADM, contentivo de la impugnación promovida por los representantes del legislador el 29 de mayo de 2002. Dicha impugnación se dirigía en contra del Auto № 003-02 del 25 de marzo de 2002, emitido por el Tribunal de Honor y Disciplina del partido, y la Sentencia 001-02 del 5 de abril de 2002, aprobada por el CDN, mediante las cuales se había resuelto y ratificado expulsarlo del partido y revocarle el mandato al cargo de legislador de la República.

El 3 de junio de 2002 "Tito" emitió además un incidente de recusación contra dos magistrados del TE: Erasmo Pinilla y Eduardo Valdés Escofferry. Alegó que el primero era primo hermano de su "enemigo" dentro del PRD, Mateo Castillero, a quien Afú había acusado de entregar un adelanto de un soborno para que diera voto favorable al proyecto CEMIS. Por ese motivo presumía que el magistrado ponente tendría un especial interés en sancionarlo, lo cual estaba contemplado como causal de impedimento.

En cuanto al segundo magistrado recusado, le cuestionaba haber emitido pronunciamientos prejuiciosos sobre el caso de expulsión y revocatoria de mandato. Según Escofferry había adelantado a los medios, el proceso del diputado iba a ser rápido y expedito. El afectado reaccionó con una negativa a ese comentario y acusó al magistrado de prejuzgamiento: "no estamos viendo imparcialidad de ninguno de los dos magistrados", dijo ${ }^{32}$. El propósito del recurso era que ambos integrantes del TE se declarasen impedidos en el proceso de impugnación presentado por Afú contra las resoluciones del PRD.

Ante la decisión del TE de no dar trámite al recurso de impugnación iniciado contra las resoluciones de expulsión y revocatoria emitidas por el partido, Afú se dirigió a la Corte Suprema de Justicia e interpuso un Recurso de Hecho, que fue acogido por Jacinto Cárdenas, magistrado suplente de Winston Spadafora ${ }^{33}$. El 20 de junio de 2002

31 GÁLVEZ F., Florencio. Caso de Afú podría llegar a la Corte. Portal Crítica, mar. 2002. Disponible en: <http:// portal.critica.com.pa/archivo/03212002/nac09.html>. Acceso el: 16 ene. 2019.

32 NAVARRO, Eliécer. Afú presenta incidente de recusación. Portal Crítica, Panamá, jun. 2002. Disponible en: <http://portal.critica.com.pa/archivo/06042002/nac02.html>. Acceso el: 16 ene. 2019.

33 PÉREZ G., Rafael. Fallan tardíamente en caso de Carlos Afú. La Prensa, Panamá, may. 2005. Disponible en: <http://impresa.prensa.com/mas_de_la_prensa/Fallan-tardiamente-caso-Carlos-Afu_0_1475102563.html>. Acceso en: 19 jun. 2018. 
el Pleno de la Corte Suprema de Justicia emitió una Resolución en la cual acogió la Advertencia de Inconstitucionalidad presentada por Afú y solicitó al TE que le remitiera las actuaciones correspondientes, como así también que suspendiera el proceso de expulsión y revocatoria hasta tanto se decidiera sobre el recurso.

El 14 de noviembre de 2002 en la sede del Tribunal Marítimo se celebró la audiencia correspondiente al proceso, en la cual estuvieron presentes todas las partes y donde se resolvió dejarlo en estado de decidir hasta tanto la Honorable Corte Suprema emitiese su fallo sobre la Advertencia de Inconstitucionalidad.

En la audiencia, el fiscal Electoral, Gerardo Solís, concedió un punto a Afú en la batalla que este libraba contra el PRD para evitar su revocatoria de mandato. Sostuvo que el legislador Afú había sido elegido por el pueblo y que no era el PRD quien podía revocar el mandato a un parlamentario de sus filas por actuar conforme a sus derechos como legislador de la República. De este modo, llamaba a resolver el tema a partir de aplicar la norma constitucional. La Corte Suprema era por tanto la única que podía definir a su juicio el futuro del recurso. El fiscal acordaba con la expulsión del partido en ese caso, pero no con la revocatoria de mandato.

Finalmente, unos años más tarde, mediante Resolución del 13 de abril de 2005, el pleno de la Corte Suprema de Justicia declaró no viable la Advertencia de Inconstitucionalidad promovida por Afú contra la Resolución № 245 del TE del 16 de agosto de 1995, en la que se aprobaban las reformas a los Estatutos del PRD. La Corte indicó que la Constitución Política era clara al establecer que, contra decisiones del TE, solo se podía admitir la acción de inconstitucionalidad más no así el resto de los procesos, es decir, consultas y advertencias de inconstitucionalidad. A ello adicionó que, en vista de que la advertencia de inconstitucionalidad había sido admitida, y encontrándose en la etapa de resolver el fondo, correspondía declarar la no viabilidad del negocio, tal como lo hizo.

Luego de que la Corte hubiera resuelto la advertencia, correspondía al TE continuar el proceso (hasta entonces suspendido a pedido de la Corte) y resolverlo. Siendo que las resoluciones impugnadas habían decidido expulsar al legislador Afú del PRD y revocarle su cargo en la Asamblea, resultaba evidente que, tras haber sido iniciado el proceso en 2002 y resuelto por la Corte recién en 2005, el período electoral y legislativo en el cual se habían iniciado los hechos (1999-2004) había transcurrido y se hallaba vencido.

Frente a lo anterior, y siendo un hecho público y notorio que Afú había renunciado al PRD y había sido postulado para las elecciones generales de 2004 como candidato a diputado por los partidos MOLIERNA, Arnulfista y Liberal Nacional; la ratificada expulsión del PRD en 2005 ya no tenía razón de ser. En segundo lugar, siendo que el período legislativo dentro del cual transcurrieron los hechos ya había vencido, tampoco cabía la revocatoria de mandato del luego devenido diputado. 
Por tanto, el TE observó que los hechos que motivaron la interposición de la demanda de impugnación habían perdido su razón de ser y había operado el fenómeno jurídico de la "sustracción de materia", que según la doctrina estaba constituido por las circunstancias de que la materia justiciable sujeta a decisión dejaba de ser tal por razones extrañas a la voluntad de la parte, no pudiendo el Tribunal emitir un pronunciamiento de mérito sobre ella. En tal virtud, los magistrados del TE declararon sustracción de la materia en dicha causa y ordenaron el archivo del expediente.

\section{CONCLUSIONES}

De forma temprana e innovadora, incluso antes de iniciada la tercera ola democratizadora (Huntington, 1994), la Constitución nacional de la República de Panamá de 1972 incorporó por primera vez la revocatoria popular. En esa oportunidad, lo hizo como causal de pérdida de la representación por parte de los gobernantes elegidos. Este artículo constitucional tuvo su reglamentación en la ley $N^{\circ} 19$, aprobada en 1980. Con las modificaciones realizadas a la Ley Fundamental en 1983, se sumó la revocatoria partidaria. Finalmente, la Constitución de 2004 dio forma plena al derecho de los ciudadanos a revocar el mandato de los diputados de libre postulación. De este modo, se completaba a nivel constitucional la adopción de la revocatoria popular y de la revocatoria partidaria en este país, reguladas por las sucesivas leyes $N^{\circ} 60$ de 2006, $N^{\circ} 14$ de 2010 y Nº 4 de 2013.

Respecto del modelo clásico de la revocatoria de mandato (la popular), en Panamá su alcance es moderado en tanto solo afecta a los cargos de diputados nacionales titulares o suplentes, y, en el nivel subnacional, a los representantes de corregimiento y a los alcaldes de distrito, ya sea partidarios o de libre postulación. El cargo de presidente está exento de toda revocatoria.

Dicho mecanismo puede implementarse una vez cumplido el primer año de mandato y antes de entrar al último, a los fines de conceder al representante un plazo de tiempo aceptable para implementar su plan de gobierno y protegerlo de la pura especulación electoralista.

En cuanto al mínimo de firmas exigido para iniciar un referendo revocatorio, en este país es bastante alto: el 30\% del padrón electoral del distrito, desalentando en parte con ello la presentación de solicitudes por la ciudadanía. Para que la revocatoria se apruebe, la legislación exige reunir la mayoría simple de los votos emitidos en el referéndum, un piso muy accesible de alcanzar, y más aún siendo que no se fija un porcentaje mínimo de participación para validar la votación.

Nótese que la normativa no establece un tope máximo a la cantidad de procesos revocatorios que pueden iniciarse por mandato. Por último, para reemplazar a 
un representante revocado asume su suplente $y$, solo en ausencia de este, se llama a elecciones para cubrir los puestos tanto de titular como de suplente

En síntesis, el diseño institucional de la revocatoria popular en Panamá es de alcance moderado. Ello se observa en varios aspectos. En primer lugar, en tanto habilita algunos puestos de carácter nacional y subnacional pero deja afuera el principal cargo de gobierno: el ejecutivo nacional. Asimismo, si bien el piso de firmas indicadas para iniciar un proceso es elevado (30\% del padrón), lo que puede impactar negativamente en el ciudadano desalentándolo a iniciar un proceso; una vez superada esta primera traba, los impedimentos disminuyen notablemente: para aprobar el revocatorio solo se exige la simple mayoría de los votos emitidos sin requerir participación mínima. También es moderado el plazo del mandato en que es posible iniciar un revocatorio: en períodos de 5 años de duración, 3 años (más del 50\%) son susceptibles de revocatoria. La exclusión del primer y último año busca evitar maniobras políticas ajenas a la finalidad del control popular. Finalmente, el reemplazo por suplente en primera instancia evita especulaciones electorales por parte de los adversarios políticos que podrían desvirtuar la cualidad societal del ejercicio de la accountability ${ }^{34}$.

En cuanto a la modalidad de revocatoria partidaria, en este trabajo se ha visto que se trata de una forma novedosa y ampliamente cuestionada en Panamá. Ello, en virtud de las profundas diferencias que presenta su procedimiento, modo de funcionamiento y efectos en comparación con la revocatoria clásica o popular (más allá de las especificidades reglamentarias de cada caso). La revocatoria partidaria constituye "una disposición única en el mundo, hasta donde conocemos, y altamente controversial"35.

No obstante, y a pesar de las controversias desatadas, la revocatoria partidaria fue "finalmente adoptada por todos los partidos"36. Para algunos, su incorporación "ha influido para fortalecer la disciplina partidaria en las bancadas en el Órgano Legislativo, y por lo tanto a su institucionalización, evitando el transfuguismo político e inestabilidad en la estructura partidaria del Órgano Legislativo" ${ }^{\prime 37}$.

Luego, las modificaciones realizadas a la Ley reglamentaria en 2010, aprobadas en su mayoría por diputados del Cambio Democrático y del Partido Panameñistas, harían casi imposible revocar el mandato a los diputados y representantes que se "saltan

\footnotetext{
34 PERUZZOTTI, Enrique; Smulovitz, Catalina (Eds.). Controlando la política. Ciudadanos y medios en las nuevas democracias latinoamericanas. Buenos Aires: Temas, 2002.

35 VALDÉS ESCOFFERRY, Eduardo. Reforma electoral en América Latina: el caso Panamá. In: Zovatto, Daniel y Orozco Henríquez, Jesús. Reforma política y electoral en América Latina. Serie Doctrina Jurídica n 418. México: Unam-IDEA Internacional, 2008. p. 761.

36 VALDÉS ESCOFFERRY, Eduardo. Reforma electoral en América Latina: el caso Panamá. In: Zovatto, Daniel y Orozco Henríquez, Jesús. Reforma política y electoral en América Latina. Serie Doctrina Jurídica n 418. México: Unam-IDEA Internacional, 2008. p. 761.

37 PÉREZ G., Rafael. Fallan tardíamente en caso de Carlos Afú. La Prensa, Panamá, may. 2005. Disponible en: <http://impresa.prensa.com/mas_de_la_prensa/Fallan-tardiamente-caso-Carlos-Afu_0_1475102563.html>. Acceso en: 19 jun. 2018.
} 
de tolda"38. Al menos hasta la reforma de 2013, donde nuevamente se suavizarían los requisitos.

En esta legislación de 2010, la revocatoria partidaria incluyó una cuota importante y decisiva de participación y control ciudadano, como instancia final necesaria para hacer efectiva la iniciativa revocadora aprobada por doble instancia partidaria. Con lo cual, si bien el mecanismo seguía siendo de iniciativa partidaria, ejecutada a través de sus órganos directivos, daba un reconocimiento a la fuente de legitimidad popular del cargo, de la que demandaba su participación en la resolución final sobre el representante.

A juicio del magistrado del Tribunal Electoral, Eduardo Valdés Escofferry, estos cambios se convirtieron en el primer impedimento para su implementación: "es muy difícil que un partido pueda aplicar la revocatoria de mandato tal como está la legislación ahora mismo" ${ }^{\prime 39}$. Para el diputado panameñista Luis Eduardo Quirós, el proceso de la revocatoria era complicado, pero debía llevarse a cabo de todos modos, porque de lo contrario se estaría traicionando al electorado que emitió su voto pensando en apoyar a la figura de un colectivo. El 1 de julio de 2014 entraría en vigencia la reforma de 2013, que daría marcha atrás con varias de estas últimas restricciones.

En lo que hace a su diseño institucional, esta forma particular de revocatoria no ha sido dispuesta para que sea la ciudadanía quién la inicie, a fin de controlar y eventualmente destituir a los gobernantes que ha votado, sino que se crea para uso de los partidos políticos respecto de los candidatos que postularon y que fueron elegidos a través de ellos.

La finalidad de uso de esta revocatoria es de tipo político, partidario e ideológico, para sancionar la falta de lealtad de un mandatario hacia el partido que canalizó su postulación. Es decir, constituye un instrumento de disciplina partidaria. Ello se diferencia radicalmente de la revocatoria popular o clásica, siendo esta un mecanismo de accountability vertical en manos de la ciudadanía, creada para desplazar a representantes que han defraudado su confianza y/o a su juicio se han desempeñado insatisfactoriamente en el cargo.

En el plano empírico, hasta el momento solo se registraron dos casos de empleo de la revocatoria en Panamá, tratándose ambos de la modalidad partidaria, y ambos ejecutados por el PRD. Efectivamente, las dos destituciones no fueron iniciadas por la ciudadanía, "de abajo hacia arriba", sino por un partido, que había postulado, aunque en momentos diferentes, a ambos representantes. Este mecanismo funcionó en los

38 BUSTAMANTE, Aminta. Revocatoria de mandato, una norma difícil de aplicar. Panamá América, Ciudad de Panamá, abr. 2012. Disponible en: <https://www.panamaamerica.com.pa/nacion/revocatoria-de-mandato-una-norma-dificil-de-aplicar-803861>. Acceso el: 23 nov. 2018.

39 VALDÉS ESCOFFERRY, Eduardo. Reforma electoral en América Latina: el caso Panamá. In: Zovatto, Daniel y Orozco Henríquez, Jesús. Reforma política y electoral en América Latina. Serie Doctrina Jurídica nº 418. México: Unam-IDEA Internacional, 2008. p. 761. 
dos casos como un instrumento de sanción partidaria (aunque por motivos diferentes), hacia adentro de la agrupación, y no como una herramienta de democracia directa para efectivizar el control y la destitución popular de los gobernantes que perdieron el apoyo ciudadano.

Por otro lado, el hecho de estar incluida en los estatutos partidarios como una herramienta a disposición del partido, constituye un incentivo de alineamiento y de buena conducta para los representantes elegidos a través de este. En tal sentido, ayudaría a los líderes a mantener el control sobre sus legisladores, reforzando a la agrupación y a su propio poder como "oligarquía" partidaria. En otras palabras, un efecto secundario de la expulsión del partido y de la revocación del cargo de algunos mandatarios es el de fomentar la obediencia y la disciplina sobre los demás representantes partidarios en ejercicio que quieran evitar un destino semejante. Es decir, la revocatoria partidaria adquiere una connotación de sanción ejemplar y disuasiva de conductas similares.

Cabe resaltar que esta modalidad de revocatoria partidaria implica el derecho del representante a interponer recursos en su defensa, que aletargan el proceso pudiendo incluso exceder el período de mandato. Lo contrario ocurre con la revocatoria popular, cuyo resultado es inmediato e inapelable.

A modo de cierre y desde una mirada integradora sobre la revocatoria partidaria surgen a esta altura numerosos interrogantes y algunas líneas de respuesta. El primero es si se la puede considerar como un mecanismo de democracia directa. En la medida en que no es iniciada ni decidida en referéndum obligatorio y vinculante por la población, no lo es. Constituye una vía institucional de destitución de representantes electos que han sido postulados por un partido, pero no se trata de un instrumento de control popular sino de disciplina partidaria. Muy lejos de viabilizar el "autogobierno del pueblo", refuerza la mediación partidaria.

Otro interrogante emerge sobre la titularidad del cargo: ¿pertenece el mismo al partido o al representante elegido por el voto del ciudadano? Si ambos respaldos son necesarios: ¿es uno de ellos más importante? ¿Es legítima una revocatoria partidaria cuando un representante elegido a través de un partido decide romper con éste pero no por ello pierde el apoyo ciudadano?

Ligado a lo anterior cabe también preguntarse si el cargo de un representante independiente, elegido directamente por los ciudadanos, y que solo puede ser alcanzado por la revocatoria clásica vale más que el de un representante postulado por un partido, sujeto además a revocatoria partidaria. Ciertamente, un representante partidario, alcanzado por ambas revocatorias (popular y partidaria), se encuentra en inferioridad de condiciones respecto de aquél que ha sido elegido directamente por el pueblo, y que solo enfrenta el riesgo de atravesar una revocatoria iniciada por éste.

Aún así, y siendo dos las formas de candidaturas permitidas en ese país, tanto independiente como partidaria, hay que recordar que el candidato tuvo la opción de 
presentarse por su cuenta. Si, no obstante, eligió las facilidades y ventajas que la postulación partidaria le ofrece, es lógico presumir entonces que con ello también está aceptando la facultad del partido para revocarlo del cargo en caso de una falta preestablecida y grave. El candidato toma así los beneficios de la pertenencia partidaria consintiendo de igual modo las herramientas de que el partido dispone para ejercer su control e imponer su disciplina. Evitar tales riesgos implicaría, por el otro lado, asumir los costos y responsabilidades de su libre postulación.

Finalmente cabe realizar un último comentario respecto de lo pionera, novedosa y amplia que resultó la adopción de la revocatoria de mandato en Panamá. La misma comenzó en 1972, incluso antes de iniciarse lo que Huntington conceptualizó como la tercera ola de la democratización que data de mediados de los años 70, incluso antes de la era de la crisis de la representación política desde fines de los 80 , incluso antes de la oleada de reformas políticas y constitucionales que signaron el subcontinente latinoamericano desde los años 90 . Fue asimismo una incorporación novedosa y amplia en tanto no solo introdujo la modalidad clásica de revocatoria de mandato sino que también adicionó la revocatoria partidaria o anti-tránsfuga.

Dicha celeridad, novedad y amplitud sin embargo contrastan en alto grado con la escasez de casos de aplicación registrados, la que puede estar sugiriendo varias causas: un desconocimiento general y una falta de aceptación y/o apropiación ciudadana de la revocatoria popular, un efectivo disciplinamiento de los mandatarios partidarios, una mayor tolerancia de los partidos respecto del accionar de los representantes, un cierto temor de dichas agrupaciones respecto de una posible desaprobación social ante un uso excesivo de la revocatoria partidaria, o simplemente la presencia de requisitos demasiado elevados que hacen de su aplicación una misión casi imposible y de su existencia una pura apariencia sin impacto tangible.

\section{REFERENCIAS}

ALTMAN, David. Democracia Directa en el continente americano: ¿autolegitimación gubernamental o censura ciudadana? Política y Gobierno, México D. F., vol. 12, n. 2, p. 203-232, 2005.

BUSTAMANTE, Aminta. Revocatoria de mandato, una norma difícil de aplicar. Panamá América, Ciudad de Panamá, abr. 2012. Disponible en: <https://www.panamaamerica.com.pa/nacion/revocatoria-de-mandato-una-norma-dificil-de-aplicar-803861 >. Acceso el: 23 nov. 2018.

CRONIN, Thomas. Direct Democracy. The Politics of Initiative, Referéndum and Recall. Cambridge: Harvard University Press, 1989.

GÁLVEZ F., Florencio. Caso de Afú podría llegar a la Corte. Portal Crítica, mar. 2002. Disponible en: <http://portal.critica.com.pa/archivo/03212002/nac09.html>. Acceso el: 16 ene. 2019. 
HERNÁNDEZ, Silvio. Panamá: Retiran inmunidad a diputado acusado de extorsión. Inter Press Service, [s.I.], 1994. Disponible en: <http://www.ipsnoticias.net/1994/12/msg076g01e-panama-retiran-inmunidad-a-diputado-acusado-de-extorsion >. Acceso el: 12 dic. 2018.

HUNTINGTON, Samuel. La Tercera ola. La democratización a finales de Siglo XX. Barcelona: Paidós Ibérica, 1994.

NAVARRO, Eliécer. Afú presenta incidente de recusación. Portal Crítica, Panamá, jun. 2002. Disponible en: <http://portal.critica.com.pa/archivo/06042002/nac02.html>. Acceso el: 16 ene. 2019.

O`DONNELL, Guillermo. Accountability horizontal: la institucionalización legal de la desconfianza política. Revista Española de Ciencia Política, Madrid, n. 11, p. 11-31, oct. 2004.

PANAMÁ. Constitución Política de la República de Panamá de 1972, con reformas de 1978 y 1983. Disponible en: <http://bdigital.binal.ac.pa/bdp/const/Constitucion197283.pdf>. Acceso en: 15 sep. 2018.

PANAMÁ. Constitución Política de la República de Panamá de 1972. Disponible en: <http://200.46.254.138/legispan/PDF_NORMAS/1970/1972/1972_028_2256.PDF>. Acceso en: 4 may. 2018.

PANAMÁ. Constitución Política de la República de Panamá. Acto Legislativo no 1 de 2004. Disponible en: <http://pdba.georgetown.edu/Constitutions/Panama/vigente.pdf>. Acceso en: 15 nov. 2018.

PANAMÁ. Ley no 14 de 2010. Que dicta medidas sobre el certificado de información de antecedentes personales, reforma el Código Electoral y adiciona un artículo al Código Penal. Disponible en: <http://docs.panama.justia.com/federales/leyes/14-de-2010-apr-13-2010.pdf >. Acceso en: 4 may. 2018.

PANAMÁ. Ley no 19 de 1980. Por la cual se deroga la Ley 6 del 10/02/1978 y se dictan disposiciones sobre la pérdida de representación ejercida por el representante de corregimiento y el suplente. Disponible en: <http://docs.panama.justia.com/federales/leyes/19-de-1980-jul-15-1980.pdf>. Acceso el: 4 may. 2018.

PANAMÁ. Ley no 4 de 2013. Que reforma y restablece artículos del Código Electoral sobre la Revocatoria de Mandato, y dicta otra disposición. Disponible en: <http://www.organojudicial.gob.pa/ cendoj/wp-content/blogs.dir/cendoj/wdatj8b3ip-ley-4-de-7-de-febrero-de-2013.pdf>. Acceso el: 5 may. 2018.

PANAMÁ. Ley n 60 de 2006. Que reforma el Código Electoral. Disponible en: <http://docs.panama.justia.com/federales/leyes/60-de-2006-jan-2-2007.pdf>. Acceso el: 15 nov. 2018.

PANAMÁ. Tribunal Electoral. Código Electoral 2013. Panamá. 2013. Disponible en http://www. tribunal-electoral.gob.pa/html/fileadmin/user_upload/publicaciones/CODIGO_ELECTORAL_01. pdf. Acceso el: 15 de julio de 2018. 
PANAMÁ. Tribunal Electoral. Impugnación contra las resoluciones J-1/94 fechada 7/12/1994 y la 01-95 fechada 4/03/1995, dictadas por el PRD. Panamá. 1995. Disponible en: http://www.oas.org/ sap/docs/DECO/legislacion/pa/Reparto\%203-1995-ADM.pdf. Acceso el: 25 de agosto de 2018.

PANAMÁ. Tribunal Electoral. Reparto 10-2002-ADM. Panamá. 2005. Disponible en: http://201.174.39.184/Fallos_Relevantes/10_2002.pdf. Acceso el: 15 de mayo de 2018.

PAYNE J., Mark; ZOVATTO G., Daniel; CARRILLO-FLÓREZ, Fernando; ALLAMAND Z., Andrés. Democracies in Development: Politics and Reform in Latin America. Washington D.C: Inter-American Development Bank - International Institute for Democracy and Electoral Assistance, 2002.

PÉREZ G., Rafael. Fallan tardíamente en caso de Carlos Afú. La Prensa, Panamá, may. 2005. Disponible en: <http://impresa.prensa.com/mas_de_la_prensa/Fallan-tardiamente-caso-Carlos-Afu_0_1475102563.html>. Acceso en: 19 jun. 2018.

PERUZZOTTI, Enrique; SMULOVITZ, Catalina (Eds.). Controlando la política. Ciudadanos y medios en las nuevas democracias latinoamericanas. Buenos Aires: Temas, 2002.

RODRÍGUEZ, Ivonne. Los doce casos más importantes de la historia democrática. La Estrella de Panamá, jun. 2014. Disponible en: <http://laestrella.com.pa/panama/politica/doce-casos-importantes-historia-democratica/23779514>. Acceso el: 3 may. 2018.

SCHEDLER, Andreas. Conceptualizing accountability. En SCHEDLER, Andreas; DIAMOND, Larry y PLATTNER, Marc. The self-refraining State: power and accountability in new democracies. London: Lynne Rienner Publishers, 1999.

SMULOVITZ, Catalina. Judicialización y Accountability Social en Argentina. XXII International Conference. Washington: Latin American Studies Association, 2001.

VALDÉS ESCOFFERRY, Eduardo. Reforma electoral en América Latina: el caso Panamá. In: ZOVATTO, Daniel y OROZCO HENRÍQUEZ, Jesús. Reforma política y electoral en América Latina. Serie Doctrina Jurídica n 418. México: Unam-IDEA Internacional, 2008. 